\title{
Prediksi Akurasi Kemenangan Pada Permainan Poker Menggunakan Algoritma C5.0 Dan WIPSO
}

\author{
M. Fariz Januarsyah ${ }^{1}$, Dr. Ermatita, M.Kom. ${ }^{2}$ \\ ${ }^{1,2}$ Program Studi Magister Ilmu Komputer, Fakultas Ilmu Komputer \\ Universitas Sriwijaya, Palembang, Indonesia \\ ${ }^{1}$ m.fariz.januarsyah@gmail.com, ${ }^{2}$ ermatita@unsri.ac.id
}

Diterima 24 Mei 2021

Disetujui 07 Juni 2021

\begin{abstract}
In the era of information technology, a lot of data can be taken from human activities based on computer systems. But the system is not only found on computers, but in all areas of human life, be it in terms of health, security, even in games where the data set from these activities becomes a database that can be used to find a new knowledge. This study aims to predict the accuracy of poker games using the Weight Improved Particle Swarm Optimization (WIPSO) algorithm for attribute selection which then uses the $\mathbf{C 5 . 0}$ algorithm to predict accuracy. Before being processed, the dataset will be changed from 11 attributes to 6 attributes. The results of this study indicate that the accuracy of the poker card will increase, when using the $\mathbf{C 5 . 0}$ algorithm the accuracy obtained is $49.952 \%$ while the accuracy obtained by the C5.0 + WIPSO algorithm is $\mathbf{5 1 . 2 \%}$.
\end{abstract}

Index Terms-Poker, Data mining, Algoritma C5.0, WIPSO.

\section{Pendahuluan}

Dalam era teknologi informasi banyak data yang dapat diambil dari kegiatan dilakukan manusia yang berhubungan dengan sistem komputer. Tetapi sistem itu bukan hanya terdapat pada komputer saja melainkan di seluruh bidang kehidupan manusia, baik itu dari segi kesehatan, keamanan bahkan di dalam permainan dengan kumpulan data dari kegiatan itu dapat menjadi database yang besar. Database ini hendaknya dapat digunakan untuk menemukan pengetahuan yang baru dalam mengambil keputusan dengan peran sebagai estimasi dan prediksi.

Permainan adalah kegiatan yang tidak dapat dilepaskan dari kehidupan manusia. Baik itu permainan fisik seperti sepak bola, atau permainan yang menggunakan strategi seperti catur. Dalam hal strategi, permainan poker merupakan salah satu permainan kartu yang mengandalkan hal tersebut [1], [2] persaingan ketat terjadi di dalam permainan poker membuat para pemainnya untuk selalu memikirkan strategi-strategi untuk menjamin akurasi kemenangan mereka [2]. Di dalam permainan pasti ada menang dan kalah, tetapi semua orang pasti ingin memenangkan permainan mereka. Untuk mencapai hal itu didapatlah sebuah solusi untuk mencapai kemenangan tersebut dalam bentuk sebuah prediksi. Prediksi kemenangan telah diterapkan diberbagai jenis permainan, seperti mencari prediksi kemenangan menggunakan metode symbolic model checking yang di optimasi dengan metode binary decision diagram untuk mencari strategi kemenangan dengan hasil gabungan dari kedua metode ini berhasil memprediksi strategi memenangkan permainan catur [3], dan penelitan yang menggunakan artificial intelligence (AI) dengan algoritma Union-Find Set dan Deep-First-Search dalam mencari keputusan untuk memenangkan permainan berbasis Hex Game System (permainan papan dengan grid berbentuk heksagon) dimana penelitian ini mencari langkah terbaik berdasarkan tiga skenario yang telah ditetapkan [4].

Untuk permainan poker, beberapa penelitian telah dilakukan diantaranya adalah dengan menggunakan algoritma naive bayes yang telah dimodifikasi dan analisis statistik, didapatkan hasil prediksi kemenangan berdasarkan kombinasi kartu yang ada dengan tingkat akurasi mencapai 92,13\% [5]. Hal prediksi juga dapat digunakan untuk memprediksi langkah yang akan diambil pemain dengan menggunakan Sequential Model dan TensorFlow, hasil dari penelitian ini adalah sebuah model neural network model training dengan tiga layer aktivasi berupa relu, relu6 dan selu, dengan menggunakan algoritma yang dapat mengubah parameter secara otomatis sehingga akurasi prediksi yang di dapat mencapai $89,09 \%$ hingga $99,31 \%$ [6]. Penelitian selanjutnya menggunakan algoritma Bayesian Networks dan Monte-Carlo Tree Search untuk membuat simulasi langkah pemain poker berdasarkan model probabilistik lawan [7]. Untuk membuat sebuah prediksi, salah satu algoritma yang sering digunakan adalah Algoritma C5.0. 
Algoritma C5.0 ini sudah digunakan pada penelitian-penelitan sebelumnya untuk mencari sebuah prediksi, dari bidang medis, algoritma C5.0 digunakan untuk memprediksi cacat setelah kelahiran berdasarkan data penyakit turunan, hipertensi diabetes dan lain-lain, dengan menggunakan C4.5 sebagai pembanding, akurasi yang di dapat oleh algoritma C5.0 mencapai 94,15\% dan C4.5 mencapai 90,87\%[8]. Penggunaan algoritma C5.0 juga dapat digabungkan dengan algoritma-algoritma yang lain sehingga membentuk algoritma hybrid, salah satunya adalah optimasi algoritma C5.0 menggunakan teori bayesian posterior, hasil dari penelitian ini adalah post pruning decision tree yang mengurangi resiko overfitting, sebelum di optimasi algoritma C5.0 menghasilkan akurasi $85,64 \%$ dan setelah algoritma itu di optimasi menghasilkan akurasi 91,25\%[9].

Ada banyak sekali metode yang dapat digunakan untuk mengoptimasi hasil dari sebuah algoritma, salah satu metode itu adalah Particle Swarm Optimization (PSO). Algoritma PSO ini diperkenalkan oleh Kennedy, Eberhart, dan Shi yang pertama sekali digunakan untuk mensimulasi tingkah laku sosial dari sekumpulan burung atau ikan [10], [11]. Algoritma PSO juga dapat digunakan dalam hal memprediksi dengan menggabungkan PSO dan Neural Network untuk memprediksi kekuatan semen pada stopes, dengan algoritma PSO bertindak sebagai architecturetuning untuk Neural Network [12]. Sedangkan pada bidang permainan agloritma PSO juga digunakan untuk meningkatkan akurasi dari support vector machine (SVM) untuk menentukan pemenang dipermainan DOTA 2 dengan PSO bertindak sebagai penentu parameter optimum untuk SVM [13].

Sejak pertama kali dikenalkan algoritma PSO ini telah menghasilkan varian-varian algoritma PSO. Salah satu varian algoritma ini adalah Weight Improved Particle Swarm Optimization (WIPSO) sebagai pengembangan dari algoritma PSO standar. Algoritma WIPSO digunakan pada penelitian untuk reduksi harmonik $H$-Bridge secara selektif pada multilevel inverter berdasarkan sumber yang setara dengan tujuan mengurangi total harmonic distortion (THD) [14], jika dibandingkan dengan algoritma PSO standar, WIPSO memiliki kelebihan dapat menemukan jawaban dengan iterasi yang lebih sedikit dengan kecepatan yang lebih tinggi.

Berdasarkan uraian di atas peneliti akan mencoba untuk menggunakan algoritma C5.0 dan algoritma WIPSO yang merupakan pengembangan dari algoritma standar PSO untuk memprediksi akurasi pada permainan poker dengan tujuan, dari penggunaan WIPSO dapat meningkatkan akurasi algoritma C5.0 dalam mencari akurasi pada permainan poker. Hasil dari penelitian ini akan di buat perbandingan akurasi antara algoritma C5.0 setelah di optimasi WIPSO dengan algoritma C5.0 sebelum optimasi WIPSO.

\section{Metode PENELITIAN}

\section{A. Data Mining}

Data mining adalah proses untuk menemukan pola yang bermanfaat bagi pengguna dari kumpulan data yang sangat banyak yang kemudian di olah dengan baik dengan teknik pembelajaran mesin, pengenalan pola, statistik dan visualisasi [15].

Kegiatan yang dilakukan manusia dipenuhi dengan data-data dibanyak bidang. Tetapi data yang banyak ini menghabiskan biaya yang banyak untuk di kumpul dan di susun dan data ini banyak yang tertimbun di dalam repositori. Karena itu penggunaan data mining dilakukan untuk mengubah data yang tertimbun itu menjadi sebuah pengetahuan baru yang dapat membantu kegiatan yang akan datang.

\section{B. Algoritma C5.0}

Algoritma C5.0 merupakan produk komersial hasil pengembangan dari algoritma $\mathrm{C} 4.5$ oleh Rulequest Research Inc [16]. C5.0 merupakan algoritma klasifikasi di dalam pembelajaran mesin dan data mining. Algoritma ini memiliki keunggulan dibandingkan dengan algoritma $\mathrm{C} 4.5$ baik itu dalam segi kemampuan ataupun efesiensi.

Di dalam algoritma C5.0 terdapat beberapa persamaan yang digunakan diantaranya adalah untuk mencari nilai entropi, nilai subset dan gain, untuk mencari nilai entropy di dalam algoritma C5.0 digunakan persamaan sebagai berikut.[17]

$$
\text { Entropi }(s)=-\sum_{i=1}^{m} p_{i} \log _{2}\left(p_{i}\right)
$$

Dimana

$\mathrm{s} \quad=$ himpunan (dataset) kasus

$\mathrm{m}=$ banyaknya partisi $\mathrm{s}$

$\mathrm{p}_{\mathrm{i}} \quad=$ probabilitas dari total kelas tertentu dibagi total kasus

Lalu nilai subset di dalam algoritma C5.0 dapat dicari dengan menggunakan persamaan sebagai berikut [17]

$$
\text { subset }(a)=\sum_{i=1}^{m} \frac{\left\|s_{i}\right\|}{|s|} \operatorname{Entropy}\left(s_{i}\right)
$$

Dimana

$\mathrm{s} \quad=$ data sampel training

a $\quad=$ atribut data

$\left|\mathrm{s}_{\mathrm{i}}\right| \quad=$ jumlah sampel untuk nilai $\mathrm{i}$

$|\mathrm{s}| \quad=$ jumlah seluruh sampel data

Entropi(s) = entropi untuk sampel yang memiliki nilai $i$

\section{Weight Improved Particle Swarm Optimization (WIPSO)Mempertahankan Keutuhan Format}

Weight Improved Particle Swarm Optimization (WIPSO) merupakan salah satu varian dari sekian banyaknya algoritma PSO, algoritma WIPSO ini meningkatkan efisiensi dari algoritma PSO standar dengan meningkatkan perhitungan faktor berat inersia, kognitif dan komponen sosial $\left(\mathrm{C}_{1}, \mathrm{C}_{2}\right)$, karena itu perhitungan di dalam algoritma ini telah berubah, 
maka rumus untuk mencari kecepatan yang baru adalah [14]

$V_{i+1}=W_{\text {new }} \times V_{i}+C_{1} \times r_{1} \times\left(P_{\text {best }_{i}}-S_{i}\right)+$

$C_{2} \times r_{2} \times\left(g_{\text {best }}-S_{i j}\right)$

Nilai $\mathrm{W}_{\text {new }}$ dapat dicari dengan rumus sebagai berikut [14] :

$$
W_{\text {new }}=W_{\min }+w \times r_{1}
$$

Sedangkan nilai $w$ dapat dicari dengan rumus [14]:

$w=W_{\max }-\left[\left(W_{\max }-W_{\min }\right) \times I T E\right] /\left(I T E_{\max }\right)(5)$

Untuk nilai Wmax dan Wmin umumnya digunakan nilai $W \max =0,9$ dan nilai $W \min =0,4$ [18]. Selanjutnya untuk mencari nilai $\mathrm{C}_{1}$ dan $\mathrm{C}_{2}$ dapat digunakan persamaan sebagai berikut [14] :

$C_{1}=C_{1 \max }-\left(C_{1 \max }-C_{1 \min }\right) \times\left(I T E / I T E_{\max }\right)(6)$

$C_{2}=C_{2 \max }-\left(C_{2 \max }-C_{2 \min }\right) \times\left(I T E / I T E_{\max }\right)(7)$

Untuk nilai $\mathrm{C}_{1 \max }$ dan $\mathrm{C}_{2 \max }$ menggunakan nilai 2 dengan nilai $\mathrm{C}_{1 \min }$ dan $\mathrm{C}_{2 \min }$ menggunakan nilai 0 [18]. Persamaan di atas dapat dijelaskan dengan dengan keterangan sebagai berikut:

$\mathrm{V}_{\mathrm{i}} \quad=$ Kecepatan partikel

$\mathrm{S}_{\mathrm{i}} \quad=$ Posisi partikel saat ini

$\mathrm{w} \quad=$ Berat inersia

$\mathrm{W}_{\min } \quad=$ Nilai inersia minimum

$\mathrm{W}_{\max }=$ Nilai inersia maksimum

$\mathrm{C}_{1} \quad=$ Koefisien akselerasi kognitif

$\mathrm{C}_{1 \text { min }}=$ Nilai awal akselerasi kognitif

$\mathrm{C}_{1 \max }=$ Nilai final akselerasi kognitif

$\mathrm{C}_{2} \quad=$ Koefisien akselerasi sosial

$\mathrm{C}_{2 \min }=$ Nilai awal akselerasi sosial

$\mathrm{C}_{2 \max }=$ Nilai awal akselerasi sosial

$\mathrm{P}_{\text {besti }} \quad=$ Posisi terbaik partikel

$\mathrm{g}_{\text {best }} \quad=$ Posisi terbaik global diantara partikel

$\mathrm{r}_{1}$ dan $\mathrm{r}_{2}=$ nilai acak antara 0 sampai 1

ITE = Nilai pengulangan saat ini

$\mathrm{ITE}_{\max }=$ maksimum nilai pengulangan

Pengujian akan dilakukan dengan menggunakan algoritma WIPSO untuk seleksi atribut terlebih dahulu yang kemudian dilanjutkan dengan algoritma C5.0. Hasil dari pemrosesan ini berupa akurasi, error dan kecepatan eksekusi yang kemudian akan digunakan sebagai data pembanding. dalam pengolahan data ini akan ditentukan beberapa atribut yang akan digunakan sebagai parameter dalam pengklasifikasian data sampel. Beberapa parameter ditentukan diawal, yaitu :

- Jumlah partikel ditentukan sebanyak 50 hingga 300.

- Nilai C1 dan C2 antara 0,5 hingga 2.

- Iterasi ditentukan antara 100 hingga 1000 kali.

- Metode validasi adalah K-fold cross validation dengan nilai 10 .

\section{Tahapan Penelitian}

Penelitian ini terdiri dari 6 (enam) tahap, diantaranya adalah studi literatur, tinjuan studi, hipotesis, pengumpulan data, pengembangan algoritma, analisa dan kesimpulan. Tahapan penelitian yang digunakan dan dapat dilihat pada Gambar 1

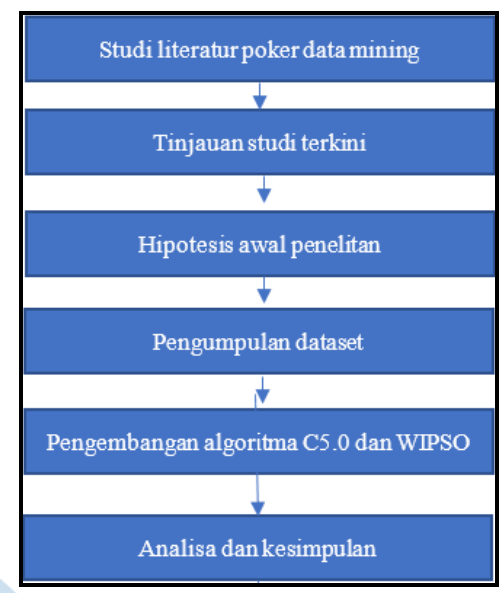

Gambar 1 Tahapan Penelitian

- Tahapan pertama pada penelitan ini adalah mencari studi literatur dan data-data yang terkait dengan permainan poker.

- Tahapan kedua adalah mencari studi terkini yang berkaitan dengan prediksi kemenangan yang ada pada bidang permainan.

- Tahapan ketiga adalah menentukan hipotesis awal dari penelitian ini, yaitu dengan menggunakan algoritma WIPSO dapat meningkatkan akurasi dari algoritma C5.0 dalam memprediksi.

- Tahapan keempat adalah mengumpulkan dataset poker dari situs https://archive.ics.uci.edu/ml/index.php dengan dataset poker yang digunakan adalah pokerhand-training-true.data yang terdiri dari 25010 data dan poker-hand-testing.data yang terdiri dari 1000000 data.

- Tahapan kelima adalah mengembangkan algoritma C5.0 dan algoritma WIPSO

- Tahapan keenam adalah hasil dan kesimpulan dari penelitian.

\section{HASIL DAN PEMBAHASAN}

\section{A. Normalisasi Data}

Sebelum dataset dapat digunakan akan dilakukan proses normalisasi data dengan menggabungkan dua atribut yang ada di dalam dataset. Dataset yang digunakan adalah poker-hand-training-true.data yang terdiri dari 25.010 data dan poker-handtesting.data dengan 1.000.000 data. Dataset tersebut memiliki 11 atribut dimana atribut 1 hingga 10 berupa 
ISSN 2085-4552

tipe dan nilai kartu dan atribut ke-11 sebagai atribut kelas. Normalisasi yang dilakukan adalah menggabungkan kedua atribut diantara sepuluh atribut manjadi satu atribut untuk memudahkan proses sehingga bentuk dataset tersebut menjadi 6 (enam) atribut, dimana atribut 1 hingga 5 adalah atribut kartu dan atribut ke-6 adalah atribut kelas.

Pada tabel 1 adalah sampel tabel yang ada pada dataset poker dengan 11 atribut, adapun keterangan dari nilai pada atribut 'tipe' yang ada pada dataset tersebut adalah, nilai 1 pada atribut tipe menandakan tipe kartu 'Hati' ( $\mathbf{v})$, nilai 2 menandakan tipe kartu 'Sekop' (\$), nilai 3 menandakan tipe kartu 'Wajik'(»), dan nilai 4 menandakan kartu 'Keriting'(^). Sedangkan untuk atribut 'nilai' untuk nilai 1 adalah kartu AS, sedangkan nilai 11 adalah kartu 'Jack', nilai 12 adalah kartu 'Queen', dan nilai 13 adalah kartu 'King'.

Sedangkan keterangan untuk nilai pada atribut poker hand dapat dapat disimpulkan menjadi, nilai 0 adalah pola kartu 'Nothing' atau 'High Hand', nilai 1 adalah pola kartu 'One Pair', nilai 2 adalah 'Two Pairs', nilai 3 adalah 'Three of a kind', nilai 4 adalah 'Straight ', nilai 5 adalah 'Flush', nilai 6 adalah 'Full House', nilai 7 adalah 'Four of a kind', nilai 8 adalah 'Straight Flush', nilai 9 adalah 'Royal Flush' dengan nilai yang memiliki nilai besar dapat mengalahkan nilai yang ada dibawahnya, dalam hal ini nilai 0 adalah nilai terkecil yang ada pada atribut 'Poker Hand'.

Tabel 1 Data sebelum Normalisasi

\begin{tabular}{|c|c|c|c|c|c|c|c|c|c|c|}
\hline T1 & N1 & T2 & N2 & T3 & N3 & T4 & N4 & T5 & N5 & H \\
\hline 1 & 10 & 1 & 11 & 1 & 13 & 1 & 12 & 1 & 1 & 9 \\
\hline 2 & 11 & 2 & 13 & 2 & 10 & 2 & 12 & 2 & 1 & 9 \\
\hline 3 & 12 & 3 & 11 & 3 & 13 & 3 & 10 & 3 & 1 & 9 \\
\hline 4 & 10 & 4 & 11 & 4 & 1 & 4 & 13 & 4 & 12 & 9 \\
\hline 4 & 1 & 4 & 13 & 4 & 12 & 4 & 11 & 4 & 10 & 9 \\
\hline 1 & 2 & 1 & 4 & 1 & 5 & 1 & 3 & 1 & 6 & 8 \\
\hline 1 & 9 & 1 & 12 & 1 & 10 & 1 & 11 & 1 & 13 & 8 \\
\hline 2 & 1 & 2 & 2 & 2 & 3 & 2 & 4 & 2 & 5 & 8 \\
\hline 3 & 5 & 3 & 6 & 3 & 9 & 3 & 7 & 3 & 8 & 8 \\
\hline 4 & 1 & 4 & 4 & 4 & 2 & 4 & 3 & 4 & 5 & 8 \\
\hline 1 & 1 & 2 & 1 & 3 & 9 & 1 & 5 & 2 & 3 & 1 \\
\hline 2 & 6 & 2 & 1 & 4 & 13 & 2 & 4 & 4 & 9 & 0 \\
\hline 1 & 10 & 4 & 6 & 1 & 2 & 1 & 1 & 3 & 8 & 0 \\
\hline 2 & 13 & 2 & 1 & 4 & 4 & 1 & 5 & 2 & 11 & 0 \\
\hline 3 & 8 & 4 & 12 & 3 & 9 & 4 & 2 & 3 & 2 & 1 \\
\hline
\end{tabular}

Setelah dataset tersebut dilakukan proses normalisasi data, hasil dari proses tersebut dapat dilihat pada tabel 2. dimana dari 11 atribut data menjadi 6 atribut.
Tabel 2 Data setelah Normalisasi

\begin{tabular}{|c|c|c|c|c|c|}
\hline Kartu 1 & Kartu 2 & Kartu 3 & Kartu 4 & Kartu 5 & $\begin{array}{c}\text { Poker } \\
\text { Hand }\end{array}$ \\
\hline 110 & 111 & 113 & 112 & 101 & 9 \\
\hline 211 & 213 & 210 & 212 & 201 & 9 \\
\hline 312 & 311 & 313 & 310 & 301 & 9 \\
\hline 410 & 411 & 401 & 413 & 412 & 9 \\
\hline 401 & 413 & 412 & 411 & 410 & 9 \\
\hline 102 & 104 & 105 & 103 & 106 & 8 \\
\hline 109 & 112 & 110 & 111 & 113 & 8 \\
\hline 201 & 202 & 203 & 204 & 205 & 8 \\
\hline 305 & 306 & 309 & 307 & 308 & 8 \\
\hline 401 & 404 & 402 & 403 & 405 & 8 \\
\hline 101 & 201 & 309 & 105 & 203 & 1 \\
\hline 206 & 201 & 413 & 204 & 409 & 0 \\
\hline 110 & 406 & 102 & 101 & 308 & 0 \\
\hline 213 & 201 & 404 & 105 & 211 & 0 \\
\hline 308 & 412 & 309 & 402 & 302 & 1 \\
\hline
\end{tabular}

B. Penerapan Algoritma C5.0

Setelah dataset dinormalisasi, langkah selanjutnya adalah melakukan proses eksperimen dengan menggunakan algoritma C5.0 sebelum di optimasi dengan WIPSO yang dapat dilihat pada gambar 2 .

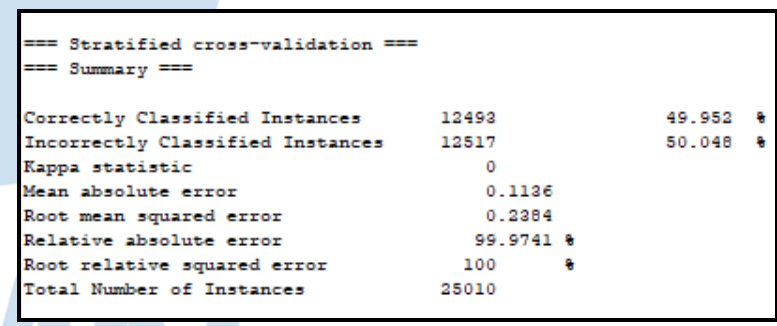

Gambar 2. Hasil Algoritma C5.0

Dari gambar tersebut dapat dilihat bahwa tingkat akurasi yang dicapai algoritma $\mathrm{C} 5.0$ berkisar pada $49,952 \%$ dengan menggunakan cross-validation sebagai metode validasi dari 25010 dataset yang digunakan.

\section{Penerapan Algoritma C5.0 + WIPSO}

Tahapan selanjutnya adalah menggunakan algoritma WIPSO sebagai seleksi atribut yang selanjutnya diproses dengan algoritma C5.0 pada data sampel. Hasil dari eksperimen tersebut dapat dilihat pada gambar 3 sebagai berikut.

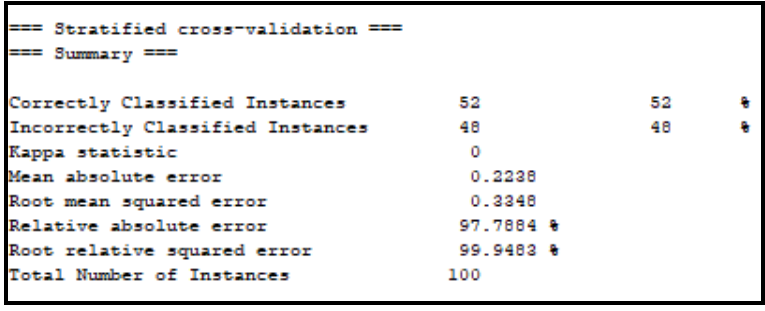

Gambar 3 Hasil Algoritma C5.0 + WIPSO 
Dari gambar tersebut dengan menggunakan metode validasi yang sama yaitu cross-validation dapat dilihat terjadinya peningkatan akurasi dari 49,952\% menjadi 52\%. Tetapi karena hasil ini masih menggunakan data sampel, langkah selanjutnya adalah melatih hasil dari algoritma ini dengan dataset poker yang dapat dilihat pada gambar 4 .

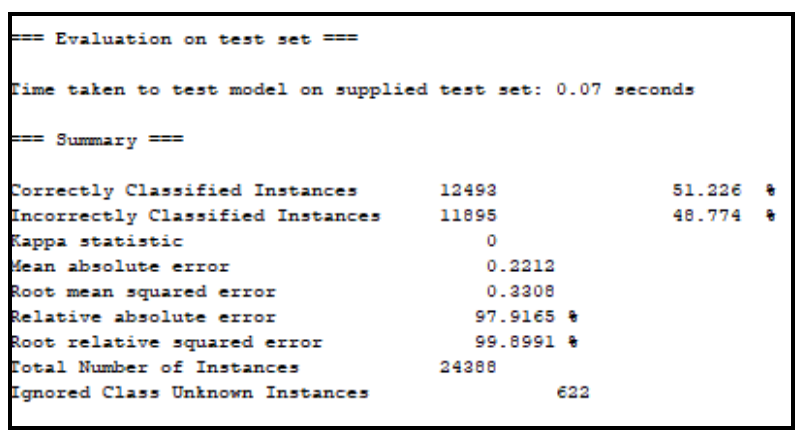

Gambar 4 Hasil Latih C5.0 + WIPSO

Dari gambar 4 akurasi yang didapatkan tetap meningkat dengan nilai $51,2 \%$, hal ini membuktikan bahwa dengan menggabungkan Algoritma WIPSO sebagai algoritma optimasi dapat meningkatkan akurasi dari algoritma C5.0.

Penerapan metode ini dilakukan pada 100 hingga 1000 data sampel. Akurasi yang didapatkan dari eksperimen ini dapat dilihat pada tabel 3 sebagai berikut.

Tabel 3 Hasil eksperimen

\begin{tabular}{|c|c|c|c|}
\hline $\begin{array}{c}\text { Jumlah } \\
\text { Sampel Data }\end{array}$ & $\begin{array}{c}\text { Akurasi } \\
\text { C5.0+WIPSO }\end{array}$ & $\begin{array}{c}\text { Hasil Latih } \\
\text { Data }\end{array}$ & $\begin{array}{c}\text { Selisih } \\
\text { Akurasi }\end{array}$ \\
\hline 100 & $52,0000 \%$ & $51,2260 \%$ & $1,2740 \%$ \\
\hline 200 & $49,0000 \%$ & $50,3425 \%$ & $0,3905 \%$ \\
\hline 300 & $52,0000 \%$ & $50,1646 \%$ & $0,2126 \%$ \\
\hline 400 & $50,5000 \%$ & $50,2696 \%$ & $0,3176 \%$ \\
\hline 500 & $53,4000 \%$ & $50,1546 \%$ & $0,2026 \%$ \\
\hline 600 & $50,1667 \%$ & $50,1606 \%$ & $0,2086 \%$ \\
\hline 700 & $49,5714 \%$ & $49,9740 \%$ & $0,0220 \%$ \\
\hline 800 & $49,3750 \%$ & $49,9840 \%$ & $0,0320 \%$ \\
\hline 900 & $53,3333 \%$ & $49,9720 \%$ & $0,0200 \%$ \\
\hline 1000 & $49,0000 \%$ & $49,9840 \%$ & $0,0320 \%$ \\
\hline
\end{tabular}

Seperti yang dilihat pada tabel 3 akurasi yang didapatkan untuk semua data sampel tetap meningkat, untuk perhitungan akurasi C5.0 + WIPSO, akurasi dari sampel data dengan jumlah data sebesar 500 dan 900 memiliki akurasi tertinggi yang disusul oleh 100 dan 300. Tetapi setelah dataset tersebut dilatih terjadi penurunan akurasi yang signifikan pada sampel 300, 500 dan 900, sedangkan akurasi dataset dengan 100 sampel tidak mengalami penurunan yang signifikan, sampel data dengan 100 data merupakan yang terbaik berdasarkan selisih dari hasil latih data dengan akurasi algoritma C5.0 dengan nilai 1,2740\%.

\section{SIMPULAN}

Hasil dari penelitian ini menghasilkan beberapa kesimpulan, yaitu :
1. Algoritma C5.0 dapat digunakan untuk melakukan prediksi akurasi poker dengan algoritma Weight Improved Particle Swarm Optimization (WIPSO) sebagai optimasi untuk meningkatkan akurasi algoritma C5.0 yang terbukti dengan adanya peningkatan sebesar $1,2740 \%$ dibandingkan dengan penggunaan algoritma C5.0 saja. Penggunaan algoritma C5.0 dari dataset tersebut mendapatkan hasil akurasi sebesar 49,952\% sedangkan algoritma C5.0 + WIPSO mendapatkan hasil sebesar 51,226\%

2. Normalisasi atribut dataset berkontribusi untuk dapat meningkatkan hasil akurasi akhir. Dengan menggabungkan atribut dataset tersebut dari 11 atribut menjadi 6 atribut terbukti dapat meningkatkan tingkat akurasi akhir

3. Untuk penelitian selanjutnya agar dapat meningkatkan hasil akhir dari algoritma C5.0 ini dapat digunakan bersamaan dengan metode boost seperti adaboost bersamaan dengan algoritma optimasi yang lain.

\section{DAFTAR PUSTAKA}

[1] T. L. MacKay, N. Bard, M. Bowling, and D. C. Hodgins, "Do pokers players know how good they are? Accuracy of poker skill estimation in online and offline players," Comput. Human Behav., vol. 31, no. 1, pp. 419-424, 2014.

[2] B. Zaman, K. Geurden, R. De Cock, B. De Schutter, and V. Vanden Abeele, "Motivation profiles of online Poker players and the role of interface preferences: A laddering study among amateur and (semi-) professionals," Comput. Human Behav., vol. 39, pp. 154-164, 2014

[3] H. Qing, "Formal verification for winning strategy of chess game," in 2017 International Workshop on Complex Systems and Networks (IWCSN), 2017, pp. 55-58.

[4] S. Li, H. Ma, and M. Ding, "Design and implementation of winning decision algorithm in Hex game system," Proc. 30th Chinese Control Decis. Conf. CCDC 2018, pp. 5909-5912, 2018.

[5] G. Ambekar, T. Chikane, S. Sheth, A. Sable, and K. Ghag, "Anticipation of winning probability in poker using data mining," in 2015 International Conference on Computer, Communication and Control (IC4), 2015, vol. 151, pp. 1-6.

[6] R. Radziukas, R. Maskeliūnas, and R. Damaševičius, "Prediction of poker moves using sequential model and tensorflow," Commun. Comput. Inf. Sci., vol. 1078 CCIS, pp. 516-525, 2019

[7] A. Heiberg, "Using Bayesian networks to model a poker player," in AAAI Workshop - Technical Report, 2013.

[8] K. Fan, Y. Ren, and Z. Yan, "Application of Birth Defect Prediction Model Based on C5.0 Decision Tree Algorithm," 2018 IEEE Int. Conf. Internet Things IEEE Green Comput. Commun. IEEE Cyber, Phys. Soc. Comput. IEEE Smart Data, pp. 1349-1354, 2018.

[9] S. Mehta and D. Shukla, "Optimization of C5.0 classifier using Bayesian theory," IEEE Int. Conf. Comput. Commun. Control. IC4 2015, 2016.

[10] J. Kennedy and R. Eberhart, "Particle swarm optimization," in Proceedings of ICNN'95 - International Conference on Neural Networks, 1995, vol. 4, no. 2, pp. 1942-1948.

[11] Y. Shi and R. Eberhart, "A modified particle swarm optimizer," in 1998 IEEE International Conference on Evolutionary Computation Proceedings. IEEE World Congress on Computational Intelligence (Cat. No.98TH8360), 1998, vol. 49, no. 5, pp. 69-73. 
[12] C. Qi, A. Fourie, and Q. Chen, "Neural network and particle swarm optimization for predicting the unconfined compressive strength of cemented paste backfill," Constr. Build. Mater., vol. 159, pp. 473-478, 2018.

[13] M. Anshori, F. Mar'i, M. W. Alauddin, and F. A. Bachtiar, "Prediction Result of Dota 2 Games Using Improved SVM Classifier Based on Particle Swarm Optimization," 3rd Int. Conf. Sustain. Inf. Eng. Technol. SIET 2018 - Proc., pp. 121-126, 2018.

[14] I. Soltani, M. Sarvi, and F. Salahian, "Various Types of Particle Swarm Optimization-based Methods for Harmonic Reduction of Cascade Multilevel Inverters for renewable energy sources," Int. J. Innov. Appl. Stud., vol. 2, no. 4, pp. 671-681, 2013
[15] D. T. Larose and C. D. Larose, Discovering Knowledge in Data. 2014.

[16] X. Wu and V. Kumar, The Top Ten Algorithms in Data Mining, vol. 53, no. 9. 2009.

[17] K. P. Wirdhaningsih, D. E. Ratnawati, U. B. Malang, D. Mining, and D. Tree, "Penerapan algoritma decision tree c5.0 untuk peramalan forex," Doro J., vol. 2, no. 8, pp. 1-6, 2013.

[18] Y. He, W. J. Ma, and J. P. Zhang, "The Parameters Selection of PSO Algorithm influencing On performance of Fault Diagnosis," MATEC Web Conf., vol. 63, no. 2016, p. 02019 2016. 